\title{
Smith-Magenis syndrome: clinical evaluation in seven Brazilian patients
}

\author{
B.F. Gamba, G.H. Vieira, D.H. Souza, F.F. Monteiro, J.J. Lorenzini, \\ D.R. Carvalho and D. Morreti-Ferreira \\ Departamento de Genética, Instituto de Biociências, \\ Universidade Estadual Paulista "Julio de Mesquita Filho", Botucatu, SP, Brasil \\ Corresponding author: D. Moretti-Ferreira \\ E-mail: sag@fmb.unesp.br
}

Genet. Mol. Res. 10 (4): 2664-2670 (2011)

Received October 20, 2010

Accepted June 14, 2011

Published October 31, 2011

DOI http://dx.doi.org/10.4238/2011.October.31.17

\begin{abstract}
Smith-Magenis syndrome (SMS) is a complex congenital anomaly characterized by craniofacial anomalies, neurological and behavioral disorders. SMS is caused by a deletion in region $17 \mathrm{p} 11.2$, which includes the $R A I 1$ gene ( $90 \%$ of cases), or by point mutation in the $R A I 1$ gene ( $10 \%$ of cases). Laboratory diagnosis is through cytogenetic analysis by GTG banding and molecular cytogenetic analysis by FISH. We carried out an active search for patients in Associations of Parents and Friends of Exceptional Children (APAE) of São Paulo and genetic centers in Brazil. Forty-eight patients were screened for mental retardation, craniofacial abnormalities and stereotyped behavior with a diagnosis of SMS. In seven of them, chromosome banding at high resolution demonstrated chromosome 17p11.2 deletions, confirmed by FISH. We also made a meta-analysis of 165 cases reported between 1982 and 2010 to compare with the clinical data of our sample. We demonstrated differences between the frequencies of clinical signs among the cases reported and seven Brazilian cases of this study, such as dental anoma-
\end{abstract}


lies, strabismus, ear infections, deep hoarse voice, hearing loss, and cardiac defects. Although the gold standard for diagnosis of SMS is FISH, we found that the GTG banding technique developed to evaluate chromosome 17 can be used for the SMS diagnosis in areas where the FISH technique is not available.

Key words: Smith-Magenis syndrome; 17p11.2; FISH; Deletion

\section{INTRODUCTION}

Smith-Magenis syndrome (SMS, OMIM \#182290) is a complex congenital disorder comprising craniofacial, neurological and behavioral abnormalities (Elsea and Girirajan, 2008). The prevalence is estimated at 1:15,000 to 1:25,000 births (Greenberg et al., 1991). SMS is caused by a deletion at the $17 \mathrm{p} 11.2$ chromosome region that includes the RAI1 gene (around $90 \%$ of cases) or by RAII gene point mutation. The classical deletions are present in $70 \%$ of patients; the size is approximately $3.5 \mathrm{Mb} ; 20 \%$ had deletions larger or smaller than the classic type. A smaller proportion, $10 \%$ of cases of SMS, have mutations in the gene RAIl (Potocki et al., 2003; Bi et al., 2004). The RAIl gene functions are linked to regulation of several genes that control specific pathways of various biological processes (Girirajan et al., 2009).

Intellectual disability is evident in all SMS patients; the major complaint of the parents regards behavior disturbances in their children. The patients were usually evaluated because of behavioral stereotypes, speech delay and sleep problems (Smith et al., 2010). SMS has distinctive facial features, but there are clinical abnormalities that overlap with other genetic disorders, such as Prader-Willi, Williams and Down syndrome.

The laboratory diagnosis for SMS uses cytogenetic analysis, by GTG banding, and molecular cytogenetic analysis, by fluorescence in situ hybridization (FISH). The commercial DNA probes for diagnosis by FISH are located on FLII and RAII genes; both are located in region 17p11.2. (Vlangos et al., 2003).

In developing countries, diagnosis and assistance to people affected by intellectual disability are generally unavailable. Moreover, the number of skilled professionals in molecular techniques such as FISH is limited. Because of this, many patients are forward associations (Associations of Parents and Friends of Exceptional Children, APAEs, in Brazil) that attend mental retardation cases; these cases are often not correctly diagnosed. This leads to a possible increase in the incidence of genetic diseases, since it is not possible to perform accurate genetic counseling.

\section{MATERIAL AND METHODS}

\section{Subjects}

We carried out an active search for possible SMS patients in APAEs of São Paulo State and in genetic centers. Patients were screened for intellectual disability, craniofacial anomalies and stereotyped behavior with a diagnosis hypothesis of SMS. All patients were clinically reviewed and subjected to classical and molecular (FISH) 
cytogenetic evaluations.

The quest at APAEs and genetic centers was made using an informative booklet. This brochure was distributed to associations that care for patients with intellectual disabilities and to clinical genetic centers. In a second step, when a suspect patient was identified, these centers contacted the genetic counseling service of UNESP in Botucatu, SP, to schedule a visit with the clinical geneticist, using a previously published check-list with clinical features (Greemberg et al., 1996; Chen et al., 1997; Allanson et al., 1999). Inclusion criteria were the presence of at least three craniofacial/skeletal muscle system abnormalities, at least one specific behavior stereotype (self-hugging/hand wringing, licking and flipping), presence or history of sleep disturbance, and presence or history of at least one self-injurious behavior (onycotillomania or polyembolokoilamania). Exclusion criteria were suspect/diagnosis of other genetic diseases, severe malformation of the central nervous system, perinatal injury or clinical status compatible with cerebral palsy, and insufficient information on study inclusion criteria. Parents provided information on pregnancy, birth conditions and psychomotor development.

We also made a meta-analysis of 165 cases reported between 1982 and 2010 to compare with the clinical data of the sample group (this list of reports is available from the authors by request). Statistical analysis was performed using the Fisher exact test.

This study was approved by the Research Ethics Committee of Botucatu Medical School, São Paulo State University/UNESP, Brazil (\#OF 014/08-CEP).

\section{Cytogenetic analyses}

Chomosome analysis was performed through high-resolution GTG banding (Yunis, 1976) of cultured peripheral blood lymphocytes. FISH was performed using two commercial Cytocell ${ }^{\circledR}$ probes, one containing the FLII gene (Cat. No. LPU007, Cytocell, USA) and the other containing the RAII gene (Cat. No. LPU019, Cytocell). The FLII probe was $80 \mathrm{~kb}$ in size, flanking distal and proximal regions of the FLII gene (Campbell et al., 1997), which has been reported to be deleted in most SMS cases (Chen et al., 1995). The RAII probe was $160 \mathrm{~kb}$ in size, flanking the distal region of the RAII gene (D17S258).

\section{RESULTS}

We evaluated 48 patients with intellectual disabilities and behavior disturbances that suggest SMS. We can observe the craniofacial features, such as brachycephaly, midface hyploplasia, broad forehead and square-shaped face, broad nasal bridge, short philtrum, everted and "tented" upper lip, and relative prognatism with age, which are present in most of the seven cases of this study. The clinical data of our seven SMS patients were similar to those of published studies except some clinical signs that were shown to be statistically significant, such as dental anomalies, strabismus, ear infections, deep hoarse voice, hearing loss, and cardiac defects (Table 1 and Figure 1). The GTG chromosome banding and high-resolution GTG chromosome banding showed seven cases with deletion 17p11.2 The FISH analysis confirmed the GTG chromosome banding results (Figure 2). 


\begin{tabular}{|c|c|c|c|c|c|c|c|c|c|c|}
\hline \multirow[t]{2}{*}{ Clinical feature } & \multicolumn{7}{|c|}{ Cases of this study } & \multicolumn{2}{|c|}{ Frequency } & \multirow[t]{2}{*}{$\mathrm{P}$} \\
\hline & 5120 & 6052 & 6339 & 6931 & 7131 & 7132 & 7571 & $\begin{array}{l}\text { This study } \\
(\mathrm{N}=7)\end{array}$ & $\begin{array}{l}\text { Literature } \\
(\mathrm{N}=165)\end{array}$ & \\
\hline \multicolumn{11}{|l|}{ Craniofacial } \\
\hline Brachycephaly & + & + & + & + & + & - & - & $5 / 7$ & $95 / 106(89.6 \%)$ & 0.1893 \\
\hline Microcephaly & + & - & + & - & - & + & - & $3 / 7$ & $9 / 56(16.0 \%)$ & 0.1199 \\
\hline Midface hypoplasia & + & + & - & + & + & + & + & $6 / 7$ & $87 / 109(79.8 \%)$ & 1.0000 \\
\hline $\begin{array}{l}\text { Broad forehead and } \\
\text { square-shaped face }\end{array}$ & + & + & + & + & + & + & + & $7 / 7$ & $64 / 82(78.0 \%)$ & 0.3367 \\
\hline Broad nasal bridge & + & + & + & + & + & + & + & $7 / 7$ & $41 / 51(80.39 \%$ & 0.3356 \\
\hline Short philtrum & + & + & + & + & + & + & + & $7 / 7$ & $11 / 11(100.0 \%)$ & 1.0000 \\
\hline Everted and "tented" upper lip & + & + & - & + & + & + & + & $6 / 7$ & $64 / 83(77.11 \%)$ & 1.0000 \\
\hline Cleft lip/palate & - & - & - & - & - & - & - & $0 / 7$ & $12 / 47(25.53 \%)$ & 0.3275 \\
\hline Relative prognathism with age & + & + & - & + & + & + & + & $6 / 7$ & $49 / 62(79.03 \%)$ & 1.0000 \\
\hline Micrognathia & - & - & + & - & - & - & - & $1 / 7$ & $12 / 28(42.86 \%)$ & 0.2197 \\
\hline \multicolumn{11}{|l|}{ Skeletal } \\
\hline Short stature & + & + & + & + & - & + & + & $6 / 7$ & $35 / 71(49.30 \%)$ & 0.1115 \\
\hline Scoliosis & + & - & - & + & - & - & + & $3 / 7$ & $23 / 53(43.40 \%)$ & 0.6971 \\
\hline Dental anomalies & + & + & + & + & + & + & + & $7 / 7$ & $4 / 11(36.36 \%)$ & $0.0128^{*}$ \\
\hline Short broad hands & + & + & + & + & + & + & + & $7 / 7$ & $\mathrm{n} / \mathrm{a}$ & $\mathrm{n} / \mathrm{a}$ \\
\hline Clinodactyly & + & + & + & + & + & + & - & $6 / 7$ & $19 / 30(63.33 \%)$ & 0.3891 \\
\hline Brachydactyly & + & + & + & + & + & + & + & $7 / 7$ & $67 / 81(82.72 \%)$ & 0.5915 \\
\hline Syndactyly & - & + & + & + & + & + & - & $5 / 7$ & $15 / 50(30.00 \%)$ & 0.0837 \\
\hline \multicolumn{11}{|l|}{ Ocular abnormalities } \\
\hline Deep-set, close-spaced eyes & + & + & + & + & + & - & + & $6 / 7$ & $47 / 72(65.28 \%)$ & 0.4156 \\
\hline Synophrys & - & + & + & + & + & + & - & $5 / 7$ & $31 / 57(54.39 \%)$ & 0.4540 \\
\hline Strabismus & + & + & + & + & + & + & + & $7 / 7$ & $39 / 67(58.21 \%)$ & $0.0400 *$ \\
\hline Iris abnormalities & + & + & + & + & + & - & - & $5 / 7$ & $10 / 23(43.48 \%)$ & 0.3898 \\
\hline \multicolumn{11}{|l|}{ Otorhinolaryngological } \\
\hline Ear abnormalities & + & + & - & + & + & - & $\mathrm{n} / \mathrm{a}$ & $4 / 6$ & $48 / 76(63.16 \%)$ & 0.6938 \\
\hline Ear infections & + & - & - & + & - & - & - & $2 / 7$ & $28 / 36(77.78 \%)$ & $0.0190^{*}$ \\
\hline Deep hoarse voice & - & - & - & + & - & - & - & $1 / 7$ & $40 / 52(76.92 \%)$ & $0.0023^{*}$ \\
\hline Hearing loss & + & - & - & + & - & - & + & $3 / 7$ & $46 / 74(62.16 \%)$ & 0.4258 \\
\hline \multicolumn{11}{|l|}{ Neurological } \\
\hline $\begin{array}{c}\text { Cognitive impairment/ } \\
\text { developmental delay }\end{array}$ & + & + & + & + & + & + & + & $7 / 7$ & $100 / 100(100.00 \%)$ & 1.0000 \\
\hline Speech delay & + & + & + & + & + & + & + & $7 / 7$ & $101 / 111(90.99 \%)$ & 1.0000 \\
\hline Motor delay & + & + & + & + & + & + & + & $7 / 7$ & $92 / 114(80.70 \%)$ & 0.3479 \\
\hline Infantile hypotonia & + & - & + & + & - & + & $\mathrm{n} / \mathrm{a}$ & $4 / 7$ & $49 / 77(63.64 \%)$ & 0.7054 \\
\hline Sleep disturbance & + & - & $\mathrm{n} / \mathrm{a}$ & + & + & + & + & $5 / 6$ & $97 / 110(88.18 \%)$ & 0.5462 \\
\hline Hyporeflexia & + & - & - & - & - & - & - & $1 / 7$ & $2 / 4(50.00 \%)$ & 0.4909 \\
\hline \multicolumn{11}{|l|}{ Behavioral } \\
\hline Self-hung & + & + & + & + & + & + & + & $7 / 7$ & $17 / 20(85.00 \%)$ & 1.0000 \\
\hline Onychotillomania & + & + & + & + & - & - & + & $5 / 7$ & $15 / 24(62.50 \%)$ & 1.0000 \\
\hline Polyembolokoilamania & + & + & + & + & - & + & + & $6 / 7$ & $14 / 23(60.87 \%)$ & 0.3717 \\
\hline Head banging/face slapping & $\mathrm{n} / \mathrm{a}$ & $\mathrm{n} / \mathrm{a}$ & - & + & $\mathrm{n} / \mathrm{a}$ & $\mathrm{n} / \mathrm{a}$ & $\mathrm{n} / \mathrm{a}$ & $1 / 2$ & $36 / 43(83.72 \%)$ & 0.3273 \\
\hline Hand biting & + & - & + & + & $\mathrm{n} / \mathrm{a}$ & + & $\mathrm{n} / \mathrm{a}$ & $4 / 5$ & $19 / 19(100.00 \%)$ & 0.2083 \\
\hline Attention seeking & + & + & + & $\mathrm{n} / \mathrm{a}$ & + & + & + & $5 / 5$ & $52 / 54(96.30 \%)$ & 1.0000 \\
\hline Aggressive behavior & + & + & + & + & + & + & + & $7 / 7$ & $62 / 67(92.54 \%)$ & 1.0000 \\
\hline Self-injurious behaviors & + & + & + & + & + & + & + & $7 / 7$ & $56 / 61(91.80 \%)$ & 1.0000 \\
\hline Hyperactivity & + & + & + & + & + & + & - & $6 / 7$ & $52 / 54(96.30 \%)$ & 1.0000 \\
\hline \multicolumn{11}{|l|}{ Other features } \\
\hline Cardiac defects & - & - & - & - & - & - & - & $0 / 7$ & $44 / 88(50.00 \%)$ & $0.0139 *$ \\
\hline Renal/urinary tract abnormalities & - & - & - & - & + & - & - & $1 / 7$ & $12 / 49(24.49 \%)$ & 1.0000 \\
\hline EEG abnormal/evident seizures & + & + & - & + & - & $\mathrm{n} / \mathrm{a}$ & $\mathrm{n} / \mathrm{a}$ & $3 / 5$ & $23 / 58(39.66 \%)$ & 0.6687 \\
\hline Male hypogonadism & - & + & - & - & - & - & - & $1 / 7$ & $21 / 60(35.00 \%)$ & 0.4116 \\
\hline Obesity & + & - & - & - & + & + & - & $3 / 7$ & $12 / 51(23.53 \%)$ & 0.3597 \\
\hline
\end{tabular}

$+=$ positive; $-=$ negative; $\mathrm{n} / \mathrm{a}=$ not available. $*$ Statistically significant values of less than 0.05 (two-tailed Fisher exact test). 

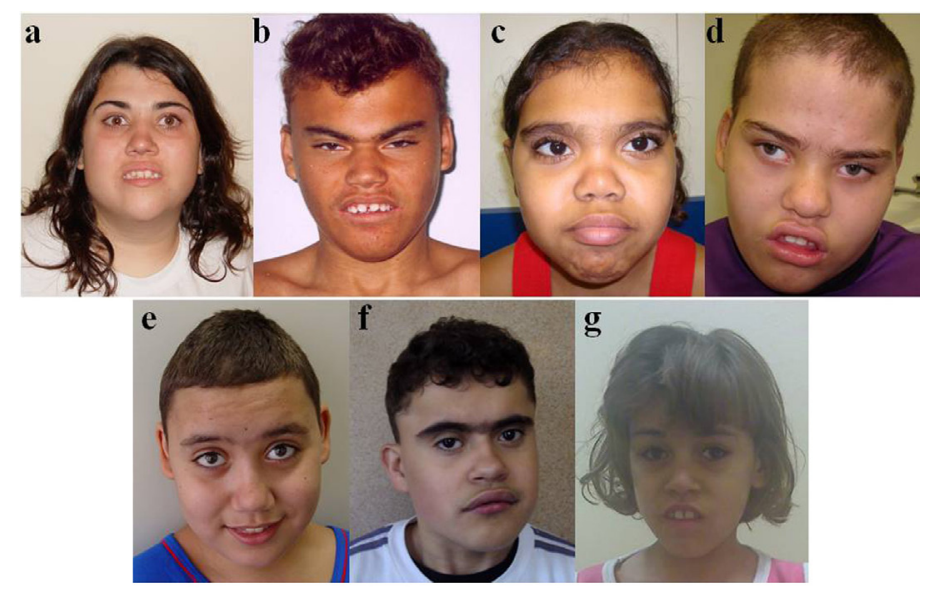

Figure 1. Facial features of the seven Brazilian Smith-Magenis syndrome patients. a. SAG5120; b. SAG6052; c. SAG6339; d. SAG6931; e. SAG7131; f. SAG7132, and g. SAG7571.

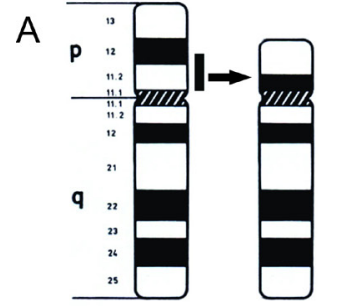

B

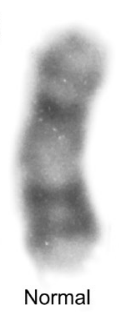

Chr 17

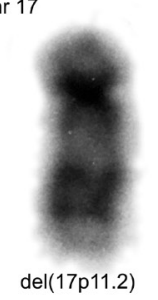

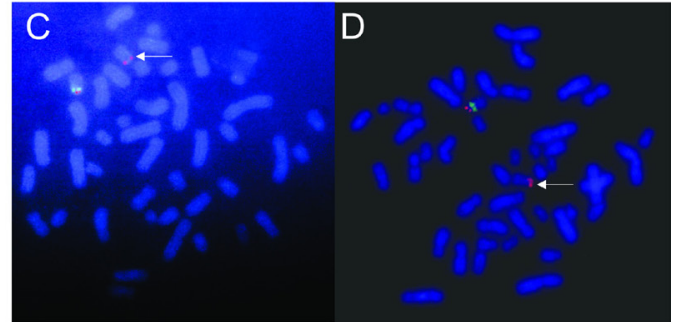

Figure 2. Representation of the 17p11.2 deletion. A. Ideogram of chromosome 17; the arrow shows the deleted region. B. Partial karyotype in GTG banding (300 bands) showing the del(17p11.2). C-D. Metaphase FISH with the specific probe for the critical region of Smith-Magenis syndrome, region control gene LIS (red, C and D), target probe gene FLII (green, C) and target probe gene RAII (green, D).

\section{DISCUSSION}

Most of the clinical signs of the seven Brazilian SMS cases are similar to what has been reported for this syndrome from other countries. The clinical signs that show significant differences are part of a set of findings reported less often in cases of SMS $(<53 \%)$. Dental anomalies and strabismus were found in all our Brazilian cases, but only 4/11 and 39/67 had these clinical signs in published reports. However, only $6 \%$ of the 165 cases described in the literature were analyzed for dental anomalies.

Deep hoarse voice, ear infections and hearing loss had a lower frequency in our group than what has been published from other countries. We believe that hearing loss is correlated with recurrent ear infections, since in a developing country, the available treatments do not reach the entire population. We did not find signs of heart disease in our patients, but this was reported in $50 \%$ of published cases.

The main signs $(>80 \%)$ of the 165 reported cases were: brachycephaly, broad nasal 
bridge, brachydactyly, speech delay, intellectual disability, sleep disturbance, and behavioral phenotype, consisting of stereotypic behavior (hug self), self-injurious behaviors (head banging/face slapping, hand biting), hyperactivity, and attention seeking. Furthermore, clinical signs such as midface hypoplasia, broad forehead and square-shaped face, short philtrum, prognathism, everted and tented upper lip, short stature, clinodactyly, and deep-set and close-spaced eyes were described at a high frequency in the patients of this study. Although Salman et al. (2004) suggested that microdeletions can be detected by cytogenetic analysis with banding resolution of 550 bands or more, we were able to find deletions in the short arm of chromosome 17 at a resolution of 300 to 400 bands. The banding and FISH gave identical results in our cases.

Until now, only two cases of Brazilian patients with SMS had been described (de Almeida et al., 1989; Llerena et al., 1998). We found differences between the frequencies of clinical signs among cases reported from other countries and our seven Brazilian cases. This information can help improve clinical screening, important for the diagnosis of cases enrolled in the exceptional children support associations. An accurate diagnosis not only provides a prognosis and a more effective treatment as well as safe and reliable genetic counseling for the family. Although the gold standard for SMS diagnosis is FISH, we conclude that GTG banding can be successfully employed to evaluate chromosome 17 where the FISH technique is not available.

\section{ACKNOWLEDGMENTS}

We thank the Parents and Friends of Exceptional Children Association (APAE) in Mauá, SP, Dr. Andrea Duarte of the Rezende Institute, Professor Fernando Figueira of Recife, PE, and Dr. Camila Bittar of the Hospital das Clinicas, Federal University of Rio Grande do

Sul, RS, for their help. Research supported by the Brazilian agency Fundação Lucentis de Apoio a Cultura, Ensino, Pesquisa e Extensão and CAPES (Federal Brazilian Found Agency), which provided a fellowship to B.F. Gamba.

\section{REFERENCES}

Allanson JE, Greenberg F and Smith AC (1999). The face of Smith-Magenis syndrome: a subjective and objective study. J. Med. Genet. 36: 394-397.

Bi W, Saifi GM, Shaw CJ, Walz K, et al. (2004). Mutations of RAI1, a PHD-containing protein, in nondeletion patients with Smith-Magenis syndrome. Hum. Genet. 115: 515-524.

Campbell HD, Fountain S, Young IG, Claudianos C, et al. (1997). Genomic structure, evolution, and expression of human FLII, a gelsolin and leucine-rich-repeat family member: overlap with LLGL. Genomics 42: 46-54.

Chen KS, Gunaratne PH, Hoheisel JD, Young IG, et al. (1995). The human homologue of the Drosophila melanogaster flightless-I gene (flil) maps within the Smith-Magenis microdeletion critical region in 17p11.2. Am. J. Hum. Genet. 56: $175-182$.

Chen KS, Manian P, Koeuth T, Potocki L, et al. (1997). Homologous recombination of a flanking repeat gene cluster is a mechanism for a common contiguous gene deletion syndrome. Nat. Genet. 17: 154-163.

de Almeida JC, Reis DF and Martins RR (1989). Interstitial deletion of (17)(p11.2). A microdeletion syndrome. Another example. Ann. Genet. 32: 184-186.

Elsea SH and Girirajan S (2008). Smith-Magenis syndrome. Eur. J. Hum. Genet. 16: 412-421.

Girirajan S, Truong HT, Blanchard CL and Elsea SH (2009). A functional network module for Smith-Magenis syndrome. Clin. Genet. 75: 364-374.

Greenberg F, Guzzetta V, Montes dO-L, Magenis RE, et al. (1991). Molecular analysis of the Smith-Magenis syndrome: a possible contiguous-gene syndrome associated with del(17)(p11.2). Am. J. Hum. Genet. 49: 1207-1218.

Greenberg F, Lewis RA, Potocki L, Glaze D, et al. (1996). Multi-disciplinary clinical study of Smith-Magenis syndrome (deletion 17p11.2). Am. J. Med. Genet. 62: 247-254. 
Llerena JR, Juan C and Almeida JCC (1998). Cytogenetic and molecular contributions to the study of mental retardation. Genet. Mol. Biol. 21: 273-279.

Potocki L, Shaw CJ, Stankiewicz P and Lupski JR (2003). Variability in clinical phenotype despite common chromosomal deletion in Smith-Magenis syndrome [del(17)(p11.2p11.2)]. Genet. Med. 5: 430-434.

Salman M, Jhanwar SC and Ostrer H (2004). Will the new cytogenetics replace the old cytogenetics? Clin. Genet. 66: 265-275.

Smith AC, Boyd K, Elsea SH, Finucane BM, et al. (2010). Smith-Magenis Syndrome. In: GeneReviews (Pagon RA, Bird TC, Dolan CR and Stephens K, eds.). University of Washington, Washington. Available at [http://www.ncbi.nlm.nih. gov/books/NBK1310/]. Accessed February 2, 2010.

Vlangos CN, Yim DK and Elsea SH (2003). Refinement of the Smith-Magenis syndrome critical region to approximately $950 \mathrm{~kb}$ and assessment of 17p11.2 deletions. Are all deletions created equally? Mol. Genet. Metab. 79: 134-141.

Yunis JJ (1976). High resolution of human chromosomes. Science 191: 1268-1270. 